\title{
Assessing self-reported risky behavior among two-wheeled vehicle users: an exploratory analysis comparing e-bikers to other riders
}

\author{
Isabelle Ragot-Court ${ }^{1 *}$, Carole Rodon ${ }^{1}$, Pierre Van Elslande ${ }^{1}$ and Jian Zhuo ${ }^{2}$
}

\begin{abstract}
The current deployment of e-bikes in large cities all over the world raises new road safety problems. The shared features of e-bikes and other types of two-wheelers, notably in terms of size and maneuverability, can lead to common road safety issues and similar accident mechanisms. This paper outlines the value of a comparative approach that includes all kinds of two-wheelers, motorized or not: bicycles, e-bikes of both the bicycle type and the scooter type, LPG and gasoline scooters, and motorcycles. For this purpose, a new self-reported risky behavior inventory was developed and its validity tested among 400 two-wheeler users in Shanghai. China, where the spread of e-bikes and other two-wheelers took place several years ago, is a useful country to study to shed light on issues that are emerging in Europe. Results indicate highly satisfactory psychometric properties of the inventory with a single-factor 12-item structure ( $52.81 \%$ of variance explained, $a=.93)$ and very satisfactory fit indexes. In terms of construct validity, the eta $(\eta)$ correlation ratio indicates its significant relation with self-reported previous accidents and with several criterion related experience variables. Furthermore, a high correlation was noted between the inventory scores and the maximum speed of the participants' vehicles. Ultimately, the inventory will enable future research to characterize and explain risky riding behaviors by riders of e-bikes compared to riders of other two-wheelers in China and, with some slight adaptations, these results can be applied to the European context.
\end{abstract}

Keywords: Risky riding behaviors, E-bikes, Power two-wheelers, Bicycle, Self-reported inventory, Comparative approach

\section{Introduction}

Mobility is evolving in many regions throughout the world, especially in large cities where bicycles seem to be gaining more and more appeal. Following this trend, the current development of e-bikes, notably in Europe, is based on a number of personal and collective benefits. Whether bicycle-style or scooter style, e-bikes are

*Correspondence: isabelle.ragot-court@univ-eiffel.fr

${ }^{1}$ Laboratory of Accident Mechanism Analysis (LMA), Gustave Eiffel University, Mediterranean Campus, 304, Chemin de la croix blanche, 13300 Salon de Provence, France

Full list of author information is available at the end of the article attractive in terms of mobility, because they allow for covering longer distances than traditional bikes with a savings of time and effort [35]. They are thus also an interesting option for various individuals: young people and less athletic or older people $[25,29,30,34,49]$. The shift from personal motor vehicles and public transport to conventional or assisted bicycles $[6,10,33]$ facilitates mobility in dense urban environments where traffic is often congested. These vehicles are therefore popular in traffic policies aimed at sustainability, as they offer more environmentally friendly solutions to cars. Unfortunately, driver and rider training are weak and there is a great 
deal of unfamiliarity with road safety and traffic rules, due to economic and historical factors [41].

Thus, the growing deployment of e-bikes in large cities raises new road safety problems which call for tailored road safety strategies and action plans to be implemented on the basis of scientific knowledge [13]. In traffic crash reports and in some research, data concerning e-bikes riders are often mixed with those of traditional bicycle riders, notably with bicycle-style e-bikes. A reason is that these e-bikes can operate in the same lanes as traditional bicycles and are covered by the same regulations [50, 52]. However, there are physical and dynamic differences between bicycles and e-bikes, notably in terms of speed capability, which impact the behavior of their users and generate different risks [13]. There is evidence of more serious injuries in crashes involving e-bikes than traditional bicycles [2]. China, where e-bikes became popular earlier than in Europe, has been affected for a longer time by the problems caused in terms of crashes and serious injuries $[1,9,27,57]$. China accounts for over three quarters of two-wheelers sold in the world [48]. Thus, not surprisingly, it has been the site of several scientific studies from the beginning of the 2000s, pointing to the specific behaviors of users of e-bikes [14, 18, 27, 51, 54, 56]. China thus constitutes a useful site for shedding light on issues that are already emerging in Europe. And the data collected there could help in the development of measures of two-wheeler riders' behavior to be founded on the basis of scientific knowledge.

The study presented in this paper is based on data collected from a population of two-wheeler riders in Shanghai city where e-bikes are a substantial part of the traffic. In this paper, we compare the risk behaviors of e-bike users with users of other types of two-wheelers (motorized or not). Despite the differences between these vehicles, there are important shared characteristics among all types of two-wheelers that distinguish them from cars, such as their smaller size, their greater maneuverability, and their capacity to ride between lines of cars. There are also behavioral similarities found between bicycle riders and motorcyclists (disobeying traffic lights/signs, illegal maneuvers, dangerous riding, etc.). Moreover, similarities in the behavior of the other road users who interact with two-wheelers, due to their smaller size, and consequent poor "conspicuity," i.e., drivers' greater difficulty in detecting them and judging their speed than is the case with cars [11]. These common features can lead to similar accident mechanisms (for example, the failure of other drivers to yield right-of-way to two-wheelers).

The currently existing tools for studying driving behavior have classically been designed to address one specific type of vehicle user: motorcycle, moped, bicycle, or electric bicycle users. It is notably the case, regarding self-reported instruments [3] 8, 16, 24, 36, 45, 47, 56. But, in the same vein as Haworth and Debnath [21], who defended the importance of comparing bikes and motorcycles, this paper outlined the value of a comparative approach that comprehensively includes all kinds of twowheelers. The benefit is that it allows identification of the behavioral risk factors that they have in common and those that distinguish them, with the purpose of implementing either shared or different safety measures.

Based on this approach, an initial exploratory study was performed which compared bicycles, e-bikes of both the bicycle and scooter types, LPG and gasoline scooters, and motorcycles, with the help of a new self-report inventory measuring risky riding behaviors [4]. A noteworthy result was that bicycle style e-bike riders are significantly different from traditional cyclists and more similar to riders of larger and more powerful two-wheelers. This result confirms the usefulness of this comparative approach.

The purpose of this paper is to present the development and construct properties of the above-mentioned inventory called the A-TRIBE (which stands for "All types of Two-wheelers' RIsky riding BEhaviors"), which was designed to compare on a common basis the different kinds of two-wheeler users. Below, the theoretical and conceptual background is presented, first for setting the methodological framework of design of this new instrument and secondly to run its first validity test.

\section{Theoretical and conceptual background}

Generally, the self-report instruments described in the literature measure risk through aberrant behaviors based on a multi-dimensional conceptualisation of risk, including dimensions such as errors, violations, and aggressive intentions (e.g. $[8,41,56]$. Another conceptualisation of behavioral risk was proposed by Dula and Geller [15], who considered risk-taking to be dangerous behaviors which are performed with or without negative intent or emotion.

As already mentioned, the previous instruments address users of specific vehicle types. Therefore, they cannot be used for comparison of risky behaviors among several types of two-wheeler users. Some of the items from these previous scales may not apply to all users of two-wheelers, such as items dealing with speeding behaviors. Examples are items such as "Open up the throttle and just 'go for it' on country roads" in the MRBQ [16], 38, or "Chase a driver who angered you," "Drive away in third gear," or "Break the speed limit" proposed in the Chinese driving questionnaire developed by Xie and Parker [55]. In addition, combining the notions of speed and type of road network in a common item, such as "Exceed the speed limit on a motorway" (MRBQ: 
[16]), makes it even less relevant for traditional bicycles and even for most e-bikes.

Designing questions about risky riding behaviors involves identifying the dimensions along which risks have been characterized in the literature. The risky nature of riding and driving behaviors is usually inferred in connection with road crashes (e.g. [17]. Specifically, studies dealing with risky behaviors and crash rates among e-bike riders in China identified a number of risk exposure factors (intentional or unintentional) associated with the likelihood of involvement in an accident.

Given the fast growth in motor vehicle use in China, factors related to users' personal experience can impact what behaviors are adopted. Riders' experience can be related to the use of a given type of two-wheeler and to the experience of the rider. Thus, Shi et al. [41] argued that, after years of riding bicycles (which were long the traditional mode of transportation in China), the sudden switch to motorized two-wheelers has caused safety problems such as reproducing the same behaviors as with a traditional bicycle when there are differences between the two vehicles, notably concerning traffic lane restrictions and the various rules governing right-of-way. Furthermore, according to Haworth and Debnath [21], illegal risk-taking can be encouraged by performance features such as the capability for high speeds and rapid acceleration, which e-bikes can achieve more easily than traditional bicycles. By extension, this observation could include comparison of two-wheelers with combustion engines to other two-wheelers with different dynamic characteristics and lesser performance. Hence, alternating between different types of two-wheelers, or past riding experience with a different type of two-wheeler, could influence exposure to risk. The implications of switching from cars to two-wheelers are also relevant. This type of shift in mode of transportation has become common for part of the population in large urban areas of China: they have either begun alternating between the two types of vehicles or abandoned the use of a car, whether for economic reasons or because of the density of traffic. In this regard, Yao and $\mathrm{Wu}$ [56] have demonstrated that those having a car driver's license are less often involved in accidents while riding two-wheelers than those without a license.

Lastly, sociodemographic variables such as gender and age are factors connected with the adoption of risky behaviors while riding both traditional bicycles and e-bikes. Men have a higher probability of engaging in risky behaviors than women, as do young and middleaged riders compared with older ones. For example, this is the case for running a red light for traditional bicycle riders and e-bikers as well [54], as is crossing an intersection in a risky manner for male e-bikers [56]. Overall, studies show that accident involvement decreases with age, whether for e-bikes [56], traditional bicycles, or motorcycles [21]. Gender also stands out as an explanatory variable in motorcycle accident involvement $[21,56]$.

\section{Study}

For the purpose of facilitating a comparative approach extended to all types of two- wheelers, we developed the A-TRIBE Inventory, a self-report instrument measuring risky riding behaviors for all types of two-wheelers. We assessed its construct validity and its criterion-validity, and more precisely its concurrent validity. The A-TRIBE's reliability and factorial structure were analyzed as well as its association with upstream factors with which risky riding behaviors are generally associated, such as number of past accidents and riding experience.

\subsection{Method}

\subsubsection{Item development}

The A-TRIBE items were developed based on a number of criteria consistent with the aforementioned definition of risk and measurement of it. As a basis of item design, we reviewed existing tools such as the MRBQ [16] and DBQ [36] to select some of the risky behaviors that would already fit the aforementioned definition of risk. The A-TRIBE items only describe behaviors and not any factors determinant of behaviors. Any references to riding and driving regulations that may lead to underreporting bias, especially regarding the peculiarities of the Chinese road context (road sharing between riders and drivers with and without riding and driving licenses as well as the recent modal shift from non-motorized to motorized vehicles for riders and drivers of various ages), were avoided. At the same time, one goal was to describe behaviors in a neutral fashion without reference to riding errors (e.g., not using words such as "Failed to notice..."). Lastly, to ensure the face validity of this new inventory, description of behaviors/situations concerned all types of two-wheelers. Consequently, mention of features specific to various types of two-wheelers (bicycles, e-bikes of the bicycle and scooter types, non-electric motor scooters, and motorcycles) was avoided. Likewise, some risky riding behaviors that refer to equipment (such as the "use of the horn") that is not relevant to all types of two-wheelers were excluded. These factors which are highly studied in the literature do not apply to a comparison between the different types of two-wheelers intended in this study.

\subsubsection{Translation into Mandarin Chinese and content validity}

Per the four authors' shared language, items were written in French before being translated into Mandarin Chinese (simplified characters). The broadly recommended translation- back-translation process with a consensus 
Table 1 The 16 items of the A-TRIBE inventory before reduction procedure

INSTRUMENT INTRODUCTION

"Over the last 6 months, how often have you adopted the following riding behaviors while riding your two-wheeler?"

RESPONSE RATING SCALE

0-never, 1-almost never, 2-occasionally, 3-often, 4-very often, 5-almost all the time

ITEMS

1-I overtook two-wheelers

2-I overtook cars

3-l let two-wheelers overtake me

4-l let a car overtake me

5-I rode between two lanes of two-wheelers

6-I rode between two lanes of vehicles

7-I kept my trajectory in front of another two-wheeler progressing in the opposite direction

8-At an intersection with traffic signals, when the light turned red, I stopped on or beyond the continuous white stop line

9-Upon seeing the traffic light turn red, I rode on the pedestrian crossing to keep on my way without stopping

10-After a full stop at a red traffic signal, I sped up as quickly as possible when the signal turned green

$11-1$ rode very close to the two-wheeler in front of me

$12-1$ rode very close to the car in front of me

13-Upon leaving my parking space, I pulled out in front of a two- wheeler that was already on the road and was imminently approaching

14-Upon leaving my parking space, I pulled out in front of a car that was already on the road and was imminently approaching

15-I maintained the same speed and trajectory when a pedestrian appeared to be about to cross the road in front of me at any time

$16-1$ crossed an intersection with no traffic lights without letting another two-wheeler approaching at a steady pace coming from my right or my left to enter ahead of me

The original Chinese version is available from the first author upon request

meeting for cross-cultural adaptation was adopted to ensure faithful translation [5, 19, 20, 28].

Thereafter, a clarity evaluation of the inventory and the entire survey questionnaire was undertaken among a panel of 13 male and seven female two-wheeler users on the campus of Tongji University in Shanghai. The questionnaire was evaluated as appropriately worded and satisfactorily comprehensible, and hence no further modifications were made.

A total of 16 items were constructed for the study. Although they were presented to the participants in Mandarin Chinese, they are presented in English for convenience in Table 1. These items provide information about various potentially hazardous riding behaviors: overtaking, progressing under potentially dangerous circumstances, riding between two lanes, risky behavior at a red traffic signal, risky lane changes, risky riding behavior at intersections, and risky riding behavior while approaching pedestrian crossings. To assess the propensity toward taking risks while riding in these situations, respondents were requested to state how frequently they had adopted each of the listed riding behaviors over the last six months (0-never, 1-almost never, 2-occasionally, 3-often, 4-very often, 5-almost all the time).

\subsubsection{Procedure and participants}

A self-administered questionnaire was used for collecting data from 400 local panelists recruited through a private
Internet survey company based in Shanghai. ${ }^{1}$ Prior Institutional Review Board (IRB) approval was obtained from both of the authors' institutions. The participants completed the questionnaire without monetary compensation. Answers were automatically and anonymously recorded, as guaranteed to the participants. The 400 participants were recruited with an equal distribution of 80 individuals within each of the five following categories: currently being solely or mainly a rider of either a bike (human-propelled; $50 \%$ male riders), a bicyclestyle e-bike (55\% males), a scooter-style e-bike $(62.5 \%$ males), a non-electric engine scooter (LPG scooter, gasoline scooter; $50 \%$ males), or a motorcycle $(72.5 \%$ males). Participants were between 18 and 65 years of age $(M=31.7$ years, $M D=31$ years, $S D=7.9)$ and were mainly from the working population (92\%).

\subsubsection{Measurements}

The research questionnaire also incorporated measured variables generally associated with driving risk. Relationships with the variables introduced below are relevant to inform criterion-related validity of the A-TRIBE inventory, and more precisely its concurrent validity [39].

Past accidents Respondents were asked to provide information about how many accidents they had been involved in over the last three years while riding their primary vehicle. Accidents were defined as crashes, collisions, or just falls, with or without serious injury, whether 
the accident was the rider's responsibility or not. With the intention of gathering information about the risky nature of some riding behaviors, a significant relationship was expected between the A-TRIBE inventory sumscores and self-reported past accidents.

Primary two-wheeler Participants provided information about whether they were only or mainly a rider of a bicycle, a bicycle-type e-bike, a scooter-type e-bike, a non-electric engine scooter (LPG scooter, gasoline scooter), or a motorcycle. The A-TRIBE inventory sumscores were expected to have a significant relationship with the type of two-wheeler ridden, referred to here as the "primary two-wheeler."

Maximum speed Respondents who rode a motorized vehicle were asked to provide information about the highest speed that their primary two-wheeler could attain: maximum speed below $20 \mathrm{~km} / \mathrm{h}$, between 20 and $50 \mathrm{~km} / \mathrm{h}$, between 51 and $70 \mathrm{~km} / \mathrm{h}$, and over $70 \mathrm{~km} / \mathrm{h}$.

Riding/driving experience variables Experience as a rider was assessed using five different measures: length of use (less than 6 months, 6 months to 2 years, 2 to 5 years, 5 to 10 years, or more than 10 years), number of riding and driving licenses obtained, switching back and forth between one type of two-wheeler and another, prior experience with an alternative type of two-wheeler (within the 6 months prior to use of the current twowheeler), and current and past car driving experience.

Socio-demographic variables: Correlations between A-TRIBE sum-scores and gender, age (classified as 18-25, $26-30,31-35$, and $36-65$ years old), and occupation were explored.

There was a need to ensure that a latent factor from the A-TRIBE inventory (adopting risky riding behaviors with two-wheelers) had relationships with the external markers listed (discriminant validity). Overall, significant correlations between the A-TRIBE inventory's item sumscores and these measurements were expected.

\section{Data analysis}

The data analyses were performed using SPSS and AMOS software.

First, the A-TRIBE inventory responses were analyzed to determine the A-TRIBE's construct and internal validity. Principal axis factoring (PAF) was employed along with split-half test analysis and computation of internal consistency (Cronbach's alpha value, 1951) for item reduction to the final 12-item structure. A Bartlett sphericity test and a Kaiser-Meyer-Olkin test of sampling adequacy ensured data factorability. Subsequently, confirmatory factor analysis (CFA) was conducted using the unweighted least squares (ULS) estimation method (Browne, 1982, cited in [22, 31].
Table 2 Final Principal Axis Factoring (PAF)'s factor loadings and communalities of the final 12-item structure of the inventory $(n=400)$ after reduction procedure

\begin{tabular}{lll}
\hline & $\begin{array}{l}\text { One factor } \\
\text { loadings }\end{array}$ & $\begin{array}{l}\text { Final } \\
\text { Communalities }\end{array}$ \\
\hline Item 2 & .617 & .410 \\
Item 6 & .602 & .393 \\
Item 7 & .575 & .362 \\
Item 8 & .654 & .451 \\
Item 9 & .727 & .539 \\
Item 10 & .700 & .524 \\
Item 11 & .711 & .573 \\
Item 12 & .831 & .708 \\
Item 13 & .836 & .679 \\
Item 14 & .853 & .715 \\
Item 15 & .776 & .618 \\
Item 16 & .768 & .590 \\
Total Variance explained & 52.81 & \\
(\%) & & \\
\hline
\end{tabular}

Next, we assessed the relationship between the A-TRIBE inventory items' sum-scores and external variables (criteria) as listed in the "Measurements" section using the eta $(\eta)$ correlation ratio [44]. After checking to ensure that assumptions of linearity, normality, and homogeneity [7] were met, F-ratios (or adjusted F-ratios when homogeneity was not met [26], were computed.

\section{Results}

\subsection{Intrinsic psychometric properties}

\subsubsection{Exploratory factor analysis}

Principal axis factoring (PAF) resulted in the extraction of items $1,3,4$, and 5 . The remaining 12 items explained $52.81 \%$ of the variance, with high factor loadings between 0.575 and 0.853 , greater than the cutoff threshold of 0.40 (Table 2).

Final communalities were high $(>0.60)$ to moderate $(>0.40)$. Only items 6 and 7 contributed slightly less to the single factor, but their communalities were still above the threshold of 0.30, which makes them acceptable. Furthermore, as the size of the sample $(n=400)$ was quite good for running factor analysis [23] 53 and the other values were consistent (internal reliability test), both of these considerations supported keeping the 12-item structure of the inventory. In addition, data factorability was supported by a significant Bartlett sphericity test $\left(\chi^{2}=2903.929 ; \mathrm{p}<0.001\right.$ and a high Kaiser -Meyer-Olkin test value of sampling adequacy $(\mathrm{KMO}=0.941)$ exceeding the minimum recommended value of 0.60 [46]. 


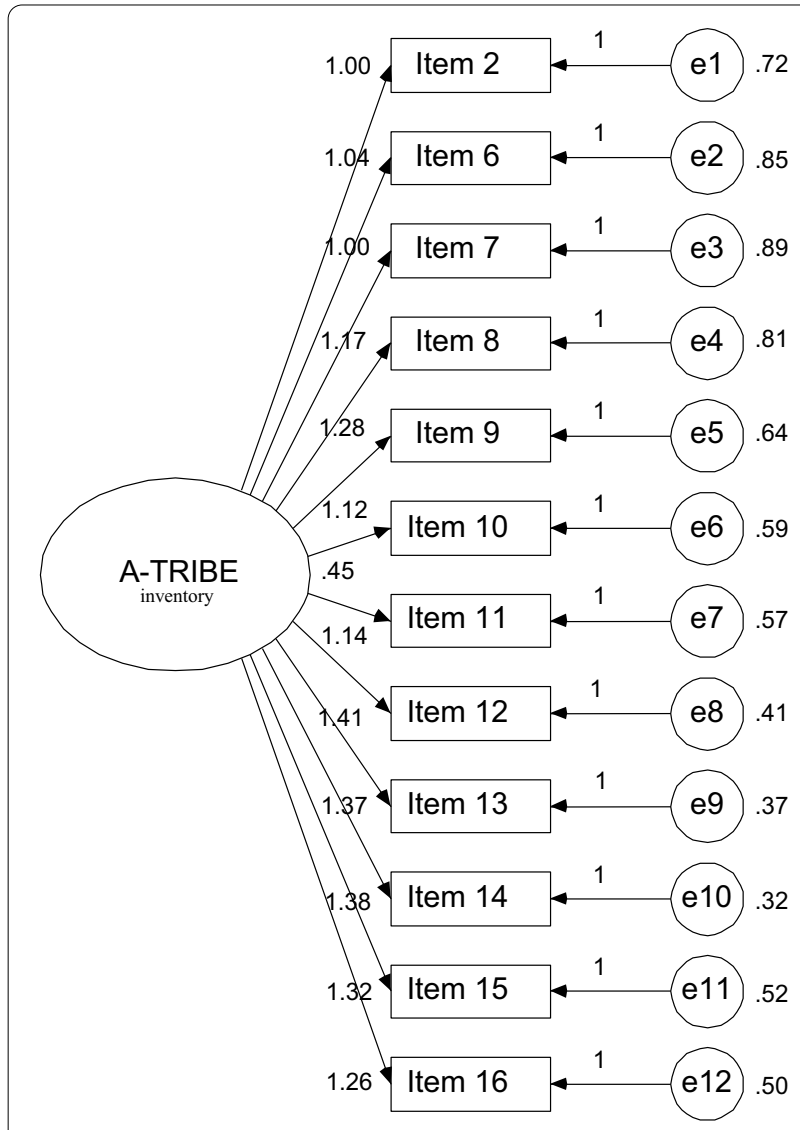

Fig. 1 CFA single-factor model testing on the 12 final items of the A-TRIBE inventory (unstandardised loadings)

Table 3 Fit indexes

\begin{tabular}{lcccccc}
\hline Models & Df & GFI & AGFI & PGFI & PRATIO & RMR \\
\hline Default & 54 & .994 & .991 & .688 & .818 & .055 \\
\hline
\end{tabular}

\subsection{Internal reliability}

The Cronbach's alpha value of the 16 items was 0.93 on the 12 remaining items. No further increases would have been achieved by eliminating more items. Similarly, split-half reliability tests were satisfactory: a correlation of 0.83 between the forms, a Spearman-Brown coefficient of 0.90 , and a Guttman split-half coefficient 0.90 .

\subsection{Confirmatory factor analysis}

Using the ULS estimation method, we tested the 12 items as a single-factor model of the A-TRIBE inventory (Fig. 1). This model yielded satisfactory fit indexes (see Table 3). GFI and AGFI had values close to 1, indicating a perfect fit; PGFI exceeded 0.60, and PRATIO was also greater than 0.60 , which is generally considered satisfactory [22]. Lastly, the RMR value was close to zero, which suggests a good fit [40].

\subsection{Criterion-related validity analysis}

The correlations of A-TRIBE inventory sum-scores were assessed with each criterion-related variable (see "Measurements" section). Thus, Table 4 provides information on the F-ratio (or adjusted F-ratio when homogeneity was not met), and eta $(\eta)$ correlation ratio, with the criterion variable as either an independent (iv) or dependent variable (dv), or the computed eta ( $\eta$ ), and lastly eta squared $\left(\eta^{2}\right)$ to indicate effect size (Sir Arthur Lewis Institute of Social and Economic Studies, 2012; Sydney, 1956; [37].

Here, results indicated mostly significant $(p)$ but low correlations $(\eta)$ of small to medium effect sizes $\left(\eta^{2}\right.$; [32, 46]. There were significant correlations as expected, even if very low, with riding/driving licenses $(\eta=0.18)$, current experience with a different type of two-wheeler (current switching between different types of two-wheeler $(\eta=0.17)$ and prior experience with an alternative type of two- wheeler $\eta=0.16$ ), and current car driving experience, $\eta=0.16$. The highest-but still low-correlations were shared by former accidents $(\eta=0.23)$, primary twowheeler $(\eta=0.20)$, past car driving behavior $(\eta=0.21)$, and maximum speed $(\eta=0.25)$. Overall, the effect sizes were small to medium (from 0.025 to 0.065). Finally, there were no significant relationships with length of use and socio-demographic variables except gender $(\eta=17)$.

\section{Discussion}

\subsection{Summary of results}

For the purpose of facilitating a comparative approach extended to all types of two- wheelers, we developed and assessed the validity of the A-TRIBE inventory. This inventory addresses all two-wheelers: users of bicycles, bicycle and scooter type e-bikes, LPG and gasoline scooters, and motorcycles. This inventory is intended to assess the propensity of riders for risk-taking through the frequency of adoption of riding behaviors common to all these two-wheeler types. An internal validity test (reliability and factorial structure) was conducted and the criterion-related validity of the A-TRIBE inventory was examined in relation to external variables that have been generally shown in the literature to be associated with risk-taking and crash rates. Regarding intrinsic psychometric properties, the A-TRIBE turned out to be very satisfactory, with a final single-factor 12-item structure (52.81\% of variance explained, $\alpha=0.93$ ), with very good fit indexes. Furthermore, based on previous research 
Table 4 F-ratio (or adjusted F-ratio), significance, eta $(\eta)$ correlation ratio, and effect size $\left(\eta^{2}\right)$ of A-TRIBE inventory with criterion variables $(\mathrm{N}=400)$

\begin{tabular}{|c|c|c|c|c|c|}
\hline Criterion variables & Df & $\begin{array}{l}\text { F } \\
\text { (or adjusted-F) }\end{array}$ & $p$ & $\eta_{\text {iv/ dv / computed }}$ & $\eta^{2}$ \\
\hline Previous accidents & 11 & 2.002 & $.027^{*}$ & $\begin{array}{l}.232 / .285 \\
.258\end{array}$ & .054 \\
\hline Primary two-wheeler & 4 & 4.295 & $.002^{*}$ & $\begin{array}{l}.204 / .400 \\
.302\end{array}$ & .042 \\
\hline Length of use & 4 & 1.573 & .181 & $\begin{array}{l}.125 / .356 \\
.240\end{array}$ & .016 \\
\hline Riding/Driving license & & 18.579 & $.000^{*}$ & $\begin{array}{l}.184 / .402 \\
.293\end{array}$ & .034 \\
\hline $\begin{array}{l}\text { Current switching between different } \\
\text { types of two-wheelers }\end{array}$ & 5 & 2.453 & $.033^{*}$ & $\begin{array}{l}.174 / .346 \\
.260\end{array}$ & .030 \\
\hline $\begin{array}{l}\text { Prior experience with an alternative type of } \\
\text { two-wheeler }\end{array}$ & 1 & 11.065 & $.001^{*}$ & $\begin{array}{l}.164 / .408 \\
.286\end{array}$ & .027 \\
\hline Current car driving experience & & 10.427 & $.001^{*}$ & $\begin{array}{l}.158 / .419 \\
.288\end{array}$ & .025 \\
\hline Past car driving experience & & 21.192 & $.000^{*}$ & $\begin{array}{l}.212 / .418 \\
.315\end{array}$ & .045 \\
\hline Maximum speed & & 9.588 & $.000^{*}$ & $\begin{array}{l}.254 / .409 \\
.327\end{array}$ & .065 \\
\hline Gender & 1 & 12.125 & $.001^{*}$ & $\begin{array}{l}.172 / .401 \\
.286\end{array}$ & .030 \\
\hline Age & 3 & 2.238 & .083 & $\begin{array}{l}.129 / .377 \\
.253\end{array}$ & .017 \\
\hline Occupation & 3 & .862 & .461 & $\begin{array}{l}.081 / .334 \\
.207\end{array}$ & .006 \\
\hline
\end{tabular}

* Significant at the threshold of $p .<.05$

regarding risky driving behaviors and road accidents, the A-TRIBE inventory's construct validity was investigated by assessing its relationships with accident history, twowheeler types, different levels of riding/driving experience, and socio-demographic variables. Overall, the eta $(\eta)$ correlation ratio tests run on the A-TRIBE sumscores indicated significant correlations, as expected. More importantly, since one goal was to gather information about the risky nature of some riding behaviors, one of the highest correlations of the A-TRIBE inventory sum-scores was with past accidents. Assessing road risks in terms of crash rates is quite common in the literature (e.g. [17]. Besides these relationships with past accident history, inventory scores also significantly correlated with experience variables typically related to road risk. Only length of time primarily riding a specific vehicle type did not significantly correlate with A-TRIBE scores. One explanation could be the recent increase in urbanization and the abrupt transition to motorized modes of transportation dating back to the 2000s in China, after years of bicycle riding. The consequences are a lack of practice and poor knowledge of road safety and traffic rules, due to economic and historical factors [41]. Despite the lack of a significant relationship of inventory scores with occupation and age, it may be interesting to examine whether population displacement between districts is sometimes accompanied by social inequalities, which would lead to reliance on specific modes of transportation and modal shifts and/or to different traffic conditions (travel time, type of transport, traffic density, etc.). Another result was the high correlation between A-TRIBE inventory scores and the maximum speed of the vehicle. This result suggests a need to further compare two-wheeler riding behaviors based on this variable rather than based on their types. That may be preferable if there is serious suspicion of engine power tampering.

Overall, the low correlations and small to medium effect sizes were reasonable considering that riding behaviors might be explained by multiple factors at different levels.

\subsection{Strengths, limitations and future research studies}

This study was carried out in Shanghai where e-bikes have long been in frequent use. Beyond some practical and cultural differences, China can be viewed as a useful source of data to shed light on issues that are already emerging in Europe. With an application perspective, the data collected there could thus help in the early definition of safety measures based on scientific knowledge. Initially focusing on e-bike riders' safety, the A-TRIBE facilitates 
the development of relevant road safety measures for all types of two-wheelers, while being adaptable to some of their specificities. This concerns both safety policies and measures such as, for example, media campaigns, enforcement, new regulations, in such a way as to be relevant to each type of two-wheelers users.

To further establish the A-TRIBE's predictive validity, forthcoming research studies would examine the relationships between the items of risky riding behaviors and other variables, such as traffic violations, incidents or accidents. Another research direction will seek to identify among cognitive and psychosocial determinants of risky riding behaviors (such as those related to personality, conative, social or cultural dimensions) some levers for modifying riding in favor of greater safety. The effectiveness of future safety programs could be increased by investigating such determinants of risky riding that may for some be shared between several types of two-wheeler users or specific to one type of user.

The data collected here with this instrument are situational. However, this inventory might be easily transferred with some slight adaptations for application in the European context. Additionally, besides some local peculiarities, the variables along which risk was measured by this instrument will help to better understand the emerging risk factors in Europe. For example, it will be useful to consider the effect of experience with the current vehicle, prior experience with alternative two-wheeler types, and the possession of an automobile driver's license as factors to be investigated in terms of their relationship to the frequency of risky behaviors.

\section{Conclusion}

Today, the growing use of e-bikes is noticeable in major cities around the world, and particularly in Europe, the mobility they afford has a number of individual and collective advantages. But for these benefits to not be offset by the negative consequences that can result from their increased use, namely the risky behavior of their users and the traffic accidents that can result from it, a number of measures must be implemented in terms of urban policies that encourage safer highway travel, aiming at zero death and serious injury. In fact, the evolution in types of road traffic implies a necessary adaptation of the road system. Riders of two-wheelers are considered vulnerable users because of the greater severity of the injuries they are likely to incur in the event of an accident compared to drivers of heavier vehicles. Despite the specificities attached to each type of two-wheelers, they share a certain number of physical and dynamic characteristics (e.g. maneuverability in traffic), as well as certain similar behaviors on the part of their users. These common features can lead to similar accident mechanisms and could suggest the implementation of similar safety measures. And as Hayworth and Debnath (2013) already mentioned with regard to cyclists and motorcyclists, road safety policies which have shown their effectiveness in preventing accidents for all types of users should prove beneficial to the safety of others. New joint actions integrating the current evolution of mobility should be developed.

To identify similar safety measures which are relevant for different types of two-wheeler riders, including e-bikes, there is a growing need to characterize and explain risky riding behaviors by e-bike users compared to users of other types of two-wheelers. The tool presented in this paper has shown its capacity to characterize the propensity toward risk-taking of e-bikers using a comparative approach with other types of two-wheelers. Regarding its design, this inventory might be easily transferred with some slight adaptations for application in the European context. It will be of significant interest when e-bikes, in addition to other traditional two-wheeler types, multiply on roads in large European cities and further complicate road interaction dynamics.

There are many implications for the prevention of accidents with injuries and/or fatalities concerning all road users, with a potential gain in investment in treatment. For example, faced with the same risky behaviors, educational content could be designed and implemented for education and training for users of different types of two-wheelers. Likewise, operational behavioral influence techniques could be developed (classical or technological persuasion, commitment, biding communication). Moreover, safety measures are needed for users of two-wheelers themselves but also for all road users who interact with them and face similar risky configurations regardless of the type of two-wheeler involved.

Road safety is now recognized as a shared responsibility between all stakeholders, integrating human fragility and the eventuality of human error. Data collection via A-TRIBE, adapted to the local context studied, should also be helping in making the traffic environment safer for these new two-wheeled users. The measures to be implemented concern the road and street infrastructure, which must be designed, built, and maintained in such a way as to integrate e-bikes, in particular, into a more harmonious and protective traffic pattern for their users and those interacting with them (e.g., pedestrians). This involves the development of a layout that promotes traffic calming measures considering the physical and dynamic specificities of these vehicles and others, as well as the implications in terms of user behavior.

\section{Acknowledgements}

The study presented here has been funded by grants from the Incentive Research program of IFSTTAR (since January 1, 2020, Gustave Eiffel University) 
and the Research Center of the Shanghai Municipality, hosted by Tongji University.

\section{Authors' contributions}

All authors read and approved the final manuscript.

\section{Declarations}

\section{Availability of data and materials}

The data that support the findings of this study are available from the corresponding author, upon request.

\section{Competing interests}

The authors declare that they have no competing interests.

\section{Author details}

'Laboratory of Accident Mechanism Analysis (LMA), Gustave Eiffel University, Mediterranean Campus, 304, Chemin de la croix blanche, 13300 Salon de Provence, France. ${ }^{2}$ College of Architecture and Urban Planning (CAUP), Tongji University, Shanghai, China.

Received: 24 November 2020 Accepted: 30 August 2021

Published online: 26 September 2021

\section{References}

1. An, K., Chen, X., Xin, F., Lin, B., \& Wei, L. (2013). Travel characteristics of e-bike users: Survey and analysis in Shanghai. Procedia-Social and Behavioral Sciences, 96, 1828-1838.

2. Baschera, D., Jäger, D., Preda, R., Z'Graggen, W. J., Raabe, A., Exadaktylos, A. K., et al. (2019). Comparison of the incidence and severity of traumatic brain injury caused by electrical bicycle and bicycle accidents-a retrospective cohort study from a Swiss level I trauma center. World Neurosurgery, 126, e1023-e1034.

3. Rodon, C., Ragot-Court, I., \& Zhuo, J. (2012). How to measure risky driving behaviors of electric and motorized two- wheelers in China? A critical review of current existing tools used towards Chinese drivers. Conference Proceedings of the Asian Conference on Social Sciences (ACSS): Working Together Towards a Sustainable World. The International Academic Forum (IAFOR), Osaka, Japan, May 2012, pp. 239-249.

4. Rodon, C., Ragot-Court, I. (2019). Assessment of risky behaviours among E-bike users: A comparative study in Shanghai. Transportation Research Interdisciplinary Perspectives, 2, 100042, 4p.

5. Brislin, R. W. (1986). The wording and translation of research instruments. In W. L. Lonner \& J. W. Berry (Eds.), Field methods in cross-cultural research (pp. 137-164). Sage.

6. Campbell, A. A., Cherry, C. R., Ryerson, M. S., \& Yang, X. (2016). Factors influencing the choice of shared bicycles and shared electric bikes in Beijing. Transportation Research Part C: Emerging Technologies, 67, 399-414

7. Carifio, J., \& Perla, R. (2007). Ten common misunderstandings, misconceptions, persistent myths and urban legends about Likert scales and Likert response formats and their antidotes. Journal of Social Sciences, 2, 106-116.

8. Cheng, A. S. K., \& Ng, T. C. K. (2010). Development of a Chinese motorcycle rider driving violation questionnaire. Accident, Analysis and Prevention, 42(4), 1250-1256.

9. Cherry, C. R., Yang, H., Jones, L. R., \& He, M. (2016). Dynamics of electric bike ownership and use in Kunming, China. Transport Policy, 45, 127-135.

10. Cherry, C., \& Cervero, R. (2007). Use characteristics and mode choice behavior of electric bike users in China. Transport Policy, 14, 247-257.

11. Clabaux, N., Brenac, T., Perrin, C., Magnin, J., Canu, B., \& Van Elslande, P. (2012). Motorcyclists' speed and "looked-but-failed-to-see" accidents. Accident Analysis and Prevention, 49, 73-77.

12. Cronbach, L. J. (1951). Coefficient alpha and the internal structure of tests. Psychometrika, 16(3), 297-334.

13. Dozza, M., Piccinini, G. B., \&Werneke, J. (2016). Using naturalistic data to assess e-cyclist vehavior. Transportation Research Part F: Traffic Psychology and Behaviour, 41, 217-226.
14. Du, W., Yang, J., Powis, B., Zheng, X., Ozanne-Smith, J., Bilston, L., \&Wu, M. (2013). Understanding on-road practices of electric bike riders: An observational study in a developed city of China. Accident Analysis and Prevention, 59, 319-326.

15. Dula, C. S., \& Geller, E. S. (2003). Risky, aggressive, or emotional driving: Addressing the need for consistent communication in research. Journal of Safety Research, 34, 559-566.

16. Elliott, M. A., Baughan, C. J., \& Sexton, B. F. (2007). Errors and violations in relation to motorcyclists' crash risk. Accident, Analysis and Prevention, 39, 491-499.

17. Elvik, R., \&Vaa, T. (2004). The Handbook of Road Safety Measures. Pergamon.

18. Fishman, E., \& Cherry, C. (2016). E-bikes in the mainstream: Reviewing a decade of research. Transport Reviews, 36(1), 72-91.

19. Flaherty, J. A., Gaviria, M., Pathak, D., Mitchell, T., Wintrob, R., Richman, J., \& Birz, S. (1988). Developing instruments for cross-cultural psychiatric research. The Journal of Nervous and Mental Disease, 176, 257-263.

20. Hambleton, R. K., Merenda, P., \& Spielberger, C. (Eds.). (2005). Adapting educational and psychological tests for cross-cultural assessment. Lawrence S. Erlbaum Publishers

21. Haworth, N., \& Debnath, A. K. (2013). How similar are two-unit bicycle and motorcycle crashes? Accident Analysis and Prevention, 58, 15-25.

22. Heeren, A., Douilliez, C., Peschard, V., Debrauwere, L., \& Philippot, P. (2011). Cross-cultural validity of the Five Facets Mindfulness Questionnaire: Adaptation and validation in a French-speaking sample. European Review of Applied Psychology, 61(3), 147-151.

23. Henson, R. K., \& Roberts, \& J.K. . (2006). Use of exploratory factor analysis in published research: Common errors and some comment on improved practice. Educational and Psychological Measurement., 66(3), 393-416.

24. Hezaveh, A., Zavareh, M., Cherry, C., \& Nordfiærn, T. (2018). Errors and violations in relation to bicyclists' crash risks: Development of the Bicycle Rider Behavior Questionnaire (BRBQ). Journal of Transport \& Health, 8, 289-298.

25. Höchsmann, C., Meister, S., Gehrig, D., Gordon, E., Li, Y., Nussbaumer, M., Rossmeissl, A., Schäfer, J., Hanssen, H., \& Schmidt-Trucksäss, A. (2018). Effect of e-bike versus bike commuting on cardiorespiratory fitness in overweight adults: A 4-week randomized pilot study. Clinical Journal of Sport Medicine, 28(3), 255-265.

26. Horn, R. A. (2016). Understanding the one-way ANOVA: Online courses. Northern Arizona University, College of Education, Educational Psychology Department. Retrieved on July 7, 2016, from http://oak.ucc.nau.edu/ rh232/courses/EPS525/Handouts/Understanding\%20the\%200ne-way\% 20ANOVA.pdf.

27. Huan, M., \& Yang, X. B. (2014). Waiting endurance time estimation of electric two-wheelers at signalized intersections. The Scientific World Journal, 2014,702197

28. International Test Commission. (2010). International test commission guidelines for translating and adapting tests. Retrieved on October 17, 2017, https://www.intestcom.org/page/16

29. Johnson, M., \& Rose, G. (2015). Extending life on the bike: Electric bike use by older Australians. Journal of Transport \& Health, 2, 276-283.

30. Langford, B. C., Cherry, C. R., Basset, D. R., Fitzhugh, E. C., \& Dhakal, N. (2017). Comparing physical activity of pedal-assist electric bikes with walking and conventional bicycles. Journal of Transport \& Health, 6 , 463-473.

31. Lubke, G., \& Muthén, B. (2004). Factor-analyzing Likert scale data under the assumption of multivariate normality complicates a meaningful comparison of observed groups or latent classes. Structural Equation Modeling, $11,514-534$

32. Miles, J., \& Shevlin, M. (2001). Applying regression and correlation: A guide for students and researchers. Sage.

33. Moser, C., Blumer, Y., \& Hille, S. L. (2018). E-bike trials' potential to promote sustained changes in car owners' mobility habits. Environmental Research Letters, 13(4), 044025.

34. Plazier, P. A., Weitkamp, G., \& Van den Berg, A. E. (2017). The potential for e-biking among the younger population: A study of Dutch students. Travel Behaviour and Society, 8, 37-45.

35. Popovich, N., Gordon, E., Shao, Z., Xing, Y., Wang, Y., \& Handy, S. (2014). Experiences of electric bicycle users in the Sacramento, California area. Travel Behaviour and Society, 1(2), 37-44. 
36. Reason, J., Manstead, A., Stradling, S., Baxter, J., \& Campbell, K. (1990) Errors and violations on the roads: A real distinction? Ergonomics, 33(10-11), 1315-1332.

37. Richardson, J.T. E. (2011). Eta squared and partial eta squared as measures of effect size in educational research. Educational Research Review, 6(2), 135-147.

38. Sakashita, C., Senserrick, T., Lo, S., Boufous, S., de Rome, L., \& Ivers, R. (2014). The Motorcycle Rider Behavior Questionnaire: Psychometric properties and application amongst novice riders in Australia. Transportation Research Part F: Traffic Psychology and Behaviour, 22, 126-139.

39. Salkind, N. J. (2010). Encyclopedia of research design. SAGE.

40. Schermelleh-Engel, K., Moosbrugger, H., \& Müller, H. (2003). Evaluating the fit of structural equation models: Tests of significance and descriptive goodness-of-fit measures. Methods of Psychological Research Online, 8, 31-51.

41. Shi, J., Bai, Y., Ying, X., \& Atchley, P. (2010). Aberrant driving behaviors: A study of drivers in Beijing. Accident Analysis and Prevention, 42(4), 1031-1040.

42. Sidney, S. (1956). Nonparametric statistics for the behavioral sciences. McGraw-Hill.

43. Sir Arthur Lewis Institute of Social and Economic studies (2012). Nominalby-Interval Association Eta, The Correlation Ratio: Quantitative Methods in Public Administration. The University of the West Indies. September 2012. Retrieved on June 20,2016, from file:///C:/Users/sony/Downloads/Quantitative\%20Methods\%20(3).pdf

44. Statistics Solutions. (2013). Correlation Ratio. Retrieved on June 20, 2016 from http://www.statisticssolutions.com/directory-of-statistical-analysescorrelation-ratio/.

45. Steg, L., \&Van Brussel, A. (2009). Accidents, aberrant behaviors, and speeding of young moped riders. Transportation Research Part F: Traffic Psychology and Behaviour, 12, 503-511.

46. Tabachnick, B. G., \& Fidell, L. S. (2007). Using multivariate statistics. Pearson/ Allyn \& Bacon.

47. Useche, S., Montoro, L., Tomas, J., \& Cendales, B. (2018). Validation of the Cycling Behavior Questionnaire: A tool for measuring cyclists' road behaviors. Transportation Research Part F: Traffic Psychology and Behaviour, 58, 1021-1030.

48. Van Schaik, J.W. (2016). China Bans E-Bike Use in Major Cities. Bike Europe connecting professionals (Vakmedianet). Retrieved from http://www. bike-eu.com/home/nieuws/2016/4/china-bans-e-bike-use-in-major-cities-10126136.

49. Wan Cauwenberg, J., De Bourdeaudhuij, I., Clarys, P., De Geus, B., \& Deforche, B. (2018). Older E-bike users: Demographic, health, mobility characteristics and cycling levels. Medicine and Science in Sports and Exercise, 50(9), 1780-1789.

50. Wei, L., Xin, F., An, K., \& Ye, Y., (2013). Comparison Study on Travel Characteristics between Two Kinds of Electric Bike. 13th COTA International Conference of Transportation Professionals (CICTP). Procedia - Social and Behavioral Sciences, 96, 1603-1610.

51. Weinert, J. X., Ma, C., Yang, X., \& Cherry, C. R. (2007). Electric two-wheelers in China - Effect on travel behavior, mode shift, and user safety perceptions in a medium-sized city. Transportation Research Record: Journal of the Transportation Research Board, 2038, 62-68.

52. Weinert, J., Ogden, J., Sperling, D., \& Burke, A. (2008). The future of electric two-wheelers and electric vehicles in China. Energy Policy, 36, 2544-2555.

53. Williams, B., Onsman, A., \& Brown, T. (2010). Exploratory factor analysis: A five-step guide for novices. Journal of Emergency Primary Health Care, 8(3), 990399.

54. Wu, C., Yao, L., \& Zhang, K. (2012). The red-light running behavior of electric bike riders and cyclists at urban intersections in China: An observational study. Accident Analysis and Prevention, 49, 186-192.

55. Xie, C., \& Parker, D. (2002). A social psychological approach to driving violations in two Chinese cities. Transportation Research Part F: Traffic Psychology and Behaviour, 5(4), 293-308.

56. Yao, L., \& Wu, C. (2012). Traffic Safety for Electric Bike Riders in China Attitudes, Risk Perception, and Aberrant Riding Behaviors. Transportation Research Record: Journal of the Transportation Research Board, 2314, 49-56.

57. Zhang, X., Cui, M., Gu, Y., Stallones, L., \& Xiang, H. (2015). Trends in electric bike-related injury in China, 2004-2010. Asia-Pacific Journal of Public Health, 27(2), NP1819-26.

\section{Publisher's Note}

Springer Nature remains neutral with regard to jurisdictional claims in published maps and institutional affiliations.

\section{Submit your manuscript to a SpringerOpen ${ }^{\circ}$ journal and benefit from:}

- Convenient online submission

- Rigorous peer review

- Open access: articles freely available online

- High visibility within the field

Retaining the copyright to your article

Submit your next manuscript at $\boldsymbol{\nabla}$ springeropen.com 